\title{
Smoke and mirrors
}

Recent months have been somewhat dispiriting for the hospitals of the NHS. One of England's premier teaching hospitals was put into 'special measures' following a visit from the Care Quality Commission; ${ }^{1}$ the Department of Health published a document giving a resumé ${ }^{2}$ of Freemantle et al $l^{3}$ showing the evidence that led the secretary of state to declare that an excess of 6,000 patients a year died if admitted to hospital at weekends, reflecting a lack of consultant cover; ${ }^{4}$ and the British Medical Association stated that it would ballot trainees on the possibility of strike actions following a breakdown of negotiations on junior doctors' contracts. ${ }^{5}$ Little wonder that morale among doctors is reported as low - and for junior doctors certainly the word is that the grass is greener on the other side of the world.

So it might be helpful to look at international comparisons and measure how well the NHS is really doing using a global yardstick. In respect of an excess mortality for patients admitted at weekends, one striking finding is that the UK is certainly not alone. Ruiz et al, ${ }^{6}$ from Imperial College's Dr Foster Unit, examined data sets from hospitals in the UK, USA, Australia and the Netherlands. Almost universally there was a greater 30-day mortality in emergency patients admitted at weekends, and indeed this extends also to elective patients. ${ }^{3,6}$ While such observational data cannot assign causality, the weekend phenomenon is 'a systematic effect across borders' and not a local problem. Clearly further information is needed to elucidate the combination of factors that lead to this universal finding - to which reduced staffing levels at all grades is a highly likely contributor; but other remediable issues such as reduced diagnostics, rota changes and unnecessary waits for patients requiring urgent treatment may all contribute. Furthermore, a recent follow-up paper by Freemantle et al acknowledged some of the excess mortality among those admitted at weekends may reflect the fact that patients are sicker overall. ${ }^{7}$ There is also the conundrum that patients who are already in hospital on a Sunday have a lower mortality on that day compared with weekdays. ${ }^{3,7}$ While the greater risk of dying after admission at a weekend is indeed shocking and requires further careful analysis, bland assumptions that this can be laid at the behaviour of UK consultants are manifestly over simplistic.
However, it is a poor defence of UK medical services to say that others are as bad as us. In this respect, the international reports by Quality Watch (by the Health Foundation and the Nuffield Trust $)^{8}$ and from the Commonwealth Fund ${ }^{9}$ repay examination. The first of these reports compares data from 2000-2013 from predominantly European, Australasian and North American sources, in primary care, acute care and cancer. The UK 'does not consistently overperform or underperform compared with the pool of 14 countries'. Performance is regarded overall as being stable or improving across the 27 or so areas considered; in some areas the UK is better - such as less profligate antibiotic use and diabetes care. In areas where UK performance has been worse than others - in the acute sector this includes asthma admissions, and mortality in acute myocardial infarction and stroke improvement occurred over 2000 to 2013, but here the UK remains stubbornly on the wrong side of the graphs illustrating relative achievement. (Parochially, in view of the substantial improvement in stroke outcome, it is pleasant to note that even though the country has not yet reached even the mean standard among the comparators, the paper notes the role of the Royal College of Physicians' stroke audit as a positive driver to improvement.)

Quality Watch ${ }^{8}$ publishes with warnings on the dangers of overuse and selective quotation from international comparisons, and refers to the euphoria generated particularly during the May general election by the Commonwealth Fund's 2014 analysis of how the US healthcare system compares internationally. This report - elegantly entitled Mirror, mirror on the wall' ${ }^{9}$ is a comparison of 11 countries - again North American, European and Australasian. The UK was ranked first overall, and also first for the four domains of Quality of Care considered (effective, safe, coordinated and patient centred), first for access to care (though third for timeliness), first for efficiency, second (behind Sweden) for equity, though tenth for healthy lives - here equal last with the US, far trailing France at the top. Perhaps more interesting than any of these individual (and perhaps somewhat surprising) rankings are the comparative figures for health expenditure; unsurprisingly the US was at the top (or bottom) at $\$ 8,508$ per capita - at the other end lay New Zealand $(\$ 3,182)$ and the UK $(\$ 3,405)$. Which

$\begin{array}{ll}\text { Members of the editorial board } \\ \text { Prof Humphrey Hodgson } & \text { Dr Cordelia Coltart } \\ \text { Editor-in-chief } & \text { International editor } \\ \text { Dr Paul Grant } & \text { Cono Ariti } \\ \text { Editorial registrar } & \text { Statistical editor }\end{array}$

Dr Na'eem Ahmed

Paul Belcher

Dr Rodger Charlton

Dr Tahseen Chowdhury

Nick Cork

Dr Kate Evans

Prof Brian Hurwitz

Prof Philip MacCarthy
Dr Angela King Prof Martin McKee

Dr Mehool Patel

Dr Roby Rakhit

Dr Ian Starke

Dr Kevin Stewart

Prof Cameron Swift 
leads to the question: if the UK can do so well on less than the other European countries with which we tend to compare ourselves - France, Germany and the Netherlands - what could we not do with the same as them?

\section{References}

1 Care Quality Commission. Addenbrookes and the Rosie Hospitals. London: CQC, 2015. Available online at www.cqc.org.uk/location/ RGT01 [Accessed 2 October 2015].

2 Department of Health. Higher risk of death associated with weekend hospitalisation. London: DoH, 2015. Available online at www.gov. uk/government/publications/higher-risk-of-death-associated-withweekend-hospitalisation [Accessed 2 October 2015].

3 Freemantle N, Richardson M, Wood J et al. Weekend hospitalization and additional risk of death: an analysis of inpatient data. $J R$ Soc Med 2012;105:74-84.

4 Hunt J; Department of Health. Making healthcare more humancentred and not system-centred (speech). London: DoH, 2015. Available online at www.gov.uk/government/speeches/makinghealthcare-more-human-centred-and-not-system-centred [Accessed 2 October 2015].
5 British Medical Association. Junior doctors plan to ballot for industrial action. BMA, 26 September 2015 Available online at bma.org.uk/news-views-analysis/news/2015/september/juniordoctors-plan-to-ballot-for-industrial-action [Accessed 2 October 2015].

6 Ruiz M, Bottle A, Aylin PP. The Global Comparators project: international comparison of 30-day in-hospital mortality by day of the week. BMJ Qual Saf 2015;24:492-504.

7 Freemantle N, Ray D, McNulty D et al. Increased mortality associated with weekend hospital admission: a case for expanded seven day services? BMJ 2015;351:h4596.

8 Kossarova L, Blunt I, Bardsley M. International comparisons of healthcare quality. London: Quality Watch, 2015. Available online at www.qualitywatch.org.uk/content/about-international-comparisons [Accessed 2 October 2015].

9 Davis K, Stremikis K, Squires S, Schoen C. Mirror, mirror on the wall, 2014 update: how the US health care system compares internationally. New York, NY: The Commonwealth Fund, 2014. Available online at www.commonwealthfund.org/publications/fund-reports/2014/jun/ mirror-mirror [Accessed 2 October 2015].

Humphrey Hodgson

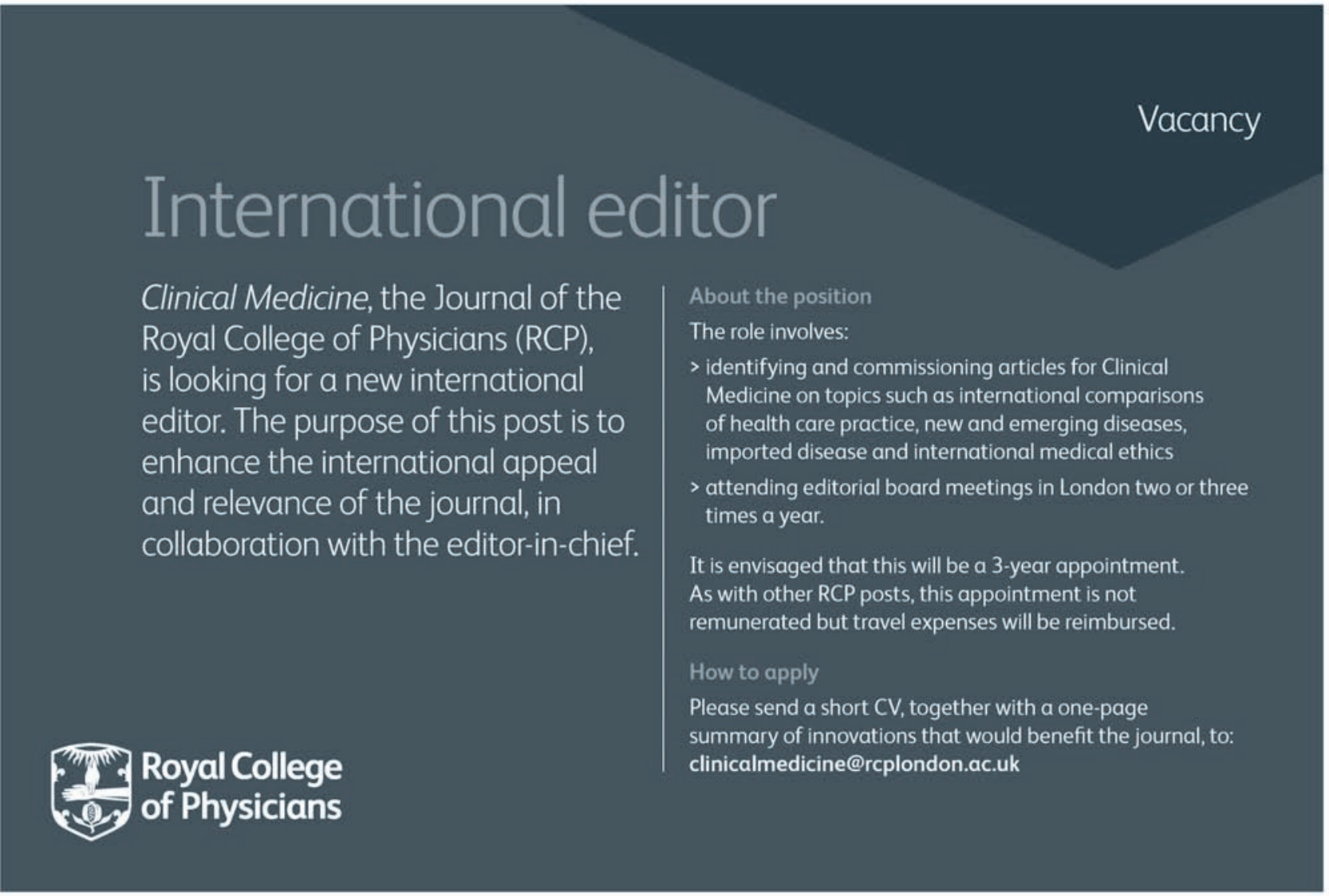

